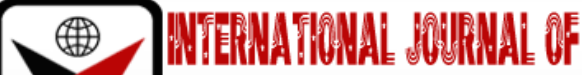

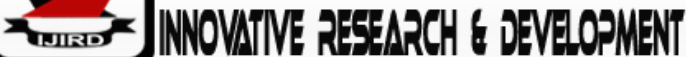

ISSN 2278-0211 (Online)

\section{An Evaluation of Post-Reclamation Management for Housing Development in Nigeria}

Ifeoluwa Akande
Lecturer, Department of Architecture,
Bells University of Technology, Ota, Ogun State Nigeria
Olabode Oyedele
Lecturer, Department of Architecture,
Bells University of Technology, Ota, Ogun State Nigeria
Damilare Sowemimo
Lecturer, Department of Architecture,
Bells University of Technology, Ota, Ogun State Nigeria
Oluwabunmi Akinde
Lecturer, Department of Architecture,
Bells University of Technology, Ota, Ogun State Nigeria

\begin{abstract}
:
Globalization brought about changes to reclamation as a practice, the impact is now being felt beyond the construction stage. Research has revealed that poor attention is given to post-reclamation management of these lands and has resulted into poor serviceability. Little or no post-construction management and maintenance budgets has become the order of the day for the government reclaimed lands and properties on it. Drainage problems, flooding and general wetness of top surrounding soil are ranked as the most pertinent consequences of poor maintenance. These, coupled with outright neglect, delay in executing repairs is seen as factors responsible for the impaired serviceability. Owing to the fact that the variables for evaluating post-reclamation management are physically measurable, observation schedule was employed to help in taking cognizance of the physical characteristics of residential buildings in the study zone, while descriptive survey method was used in selecting the study sites. It is also noteworthy that 3-sites which are reclaimed for residential purposes was considered for the study. This was done on the basis that they share similar but yet distinct properties. The study shows that lands obtained through this means require greater maintenance attention than naturally occurring lands, so as to prevent excessive degradation.
\end{abstract}

Keywords: Degradation, land, maintenance, management, post-reclamation

\section{Introduction}

Land is a finite resource in the current globalization era.Towns and cities along the coastline have become prominent and as important contributor to physical development and beautiful master piece, as lands along this line could be reclaimed and put to different uses. The attractiveness of the coastline coupled with the rate of urbanization (need for more lands) in most urban centers, Lagos inclusive, made way for the idea of reclaiming lands from seas and wetland. Realizing the huge potential of land reclamation, the Lagos State Government has been supporting and recently pursuing a number of projects in the wetland and coast line areas of the state.

\subsection{Statement of Research Problem}

Despite many of numerous technological advancements to solving urban sustainability problems and the overall physical development, there remains a great degree of clarity and uncertainty surrounding the impact of human activity on growth processes, environmental quality and management processes. In today's developing world, there is problem of rapid population growth and increasing urbanization rate. This unprecedented development comes with a handful of changes in urban setup - which could either be prospective and problematic, hence regarded as a stressor to human development.

The Lagos Island is a densely populated low-lying coastal area, with a dense network of roads and buildings, and several inland waterways including the Lagos Lagoon which empties into the Atlantic. The peculiar characteristics of the study area and the demand for residential land make it necessary to examine the role of human development on wetland loss. The unique topographical pattern of Lekki-Epe corridor as a wetland environment explains that in the course of developing land for housing construction, developers have sand-filled some of the existing wetlands/water ways. 
However, in areas such as Ikoyi, Marina and Victoria Island with a relatively flat elevation, sinking buildings and flooding has posed a major concern owing to ocean surge resulting from land being a reclaimed from the sea. Against this backdrop, it is justifiable to say there is such a need to evaluate the post-reclamation management as a way to address its profound impact on urban integrity, improve the quality of the environment and regain urban aesthetics.

\subsection{Aim and Objectives}

The aim of this paper is to evaluate post-reclamation management on housing development for a functional and aesthetically pleasing model city such a Lagos state Nigeria.

In order to achieve the aim, the following specific objective was pursued:

- To examine the concept of land reclamation viz social and environmental considerations;

- To highlight the aesthetic and architectural value of housing development along the coastline; and

- To assess the level of post-reclamation management to the built-up environment on human well-being.

\subsection{Justification}

Human activities are increasingly altering the composition of coastal line and wetland leading into increasing coastline urbanization and number of artificial islands. Ever increasing population, industrialization and human exploitation are the major catalyst that speeds up this development since more lands are required to accommodate land use changes.

In Lagos, a large number residential estate development along the peninsula is sited on artificial islands, most of which are reclaimed along the coastline; Banana Island, some part of Victoria Island and more recently is the Eko Atlantic City. Now that partial or full land reclamation practice has become a new order in acquiring lands for residential development bringing comfort and peaceful lifestyle owing to natural splendor, a thorough examination of this development is no doubt a necessity. This is addressed with a need to focus on the anthropogenic changes and postreclamation management resulting from the impact of human activities through intense development and land alteration.

\subsection{Overview of Land Reclamation in Lagos}

In Lagos, most of the land reclaimed are used basically for the provision residential area and commercial or mix development. This action is made to meet the demand for development and reduce population pressure. At the same time, it is viewed and regarded as one of the tools that attract private developers and encourage public private partnership to investment hugely in solving housing deficit issue arising from overpopulation. This scenario shows that coastal land reclamation is vital towards economic viability since it's a means that contributes to the ever-increasing economy of Lagos. With an increasing population, it will slowly cause problems to the federal and state government related to the public facilities and infrastructures inadequacies.

History of land reclamation in Lagos reported by (Aina, Ata, \& K.O., 2002), shows that earliest reclamation efforts was limited to hinterland marshy sites, interwoven within the mainland, the sites were reclaimed by the dry sand filling technique, which involves borrowing, transporting, spreading, and compacting fill material on site.

The history further shows that, changes in the city caused by exploding population, industrial, communication, and transportation growth, led to large scale reclamation of coastal parts of the city such as; Lekki, Maroko, Ajah, Victoria Garden City and Ikota. Hydraulic sand filling technology required for reclaiming large coastal lands was imported because it was not available locally.

\subsubsection{Concept of Land Reclamation}

Human life does not just exist in isolation but with everyday interaction with its immediate environment. The virtue of living is characterised by the levels of development that exist therein, and thus relative to why human is inseparable from using the environment, which also involves exploitation of the needed raw materials. Such activity can affect positively or negatively the environment, and in many cases, it leaves a permanent track. The exploitation or change in use of the surface of the earth or any of its constituent requires a thought over through effective management and/or development. In other words, to expand cities and make way for new development, new areas are needed. This then suggests that change is inevitable from using coastline, waterways and wetlands to other functional purposes.

Land reclamation from seas and wetlands around the world is not an entirely new practice. It entails dredging and transporting large amount of sand from the sea-bed to create an artificial land for infrastructural and industrial development $(Y, 2012)$. Reclamation measures can be considered as systems for regulating environmental conditions for the purpose of creating optimal conditions for growth and development of biotic assemblage, particularly for physical development purposes. Large parts of Netherlands and many coastlines along Hong Kong, North Korea, South Korea and Mainland China are reclaimed lands. Main parts of Helsinki in Finland, Yas Island of Abu Dhabi and Eko Atlantic of Lagos are just a few of the many cases of land reclamation activities around the world. (R, P, M, \& J, 2005) reports the series of land reclamation works in the United Arab Emirates at 200kmsq. To put in perspective, that is the size of 18,519 football pitches put together. Land reclamation activities have generated mixed responses in the academia. For instance, (Priyandes \& Majid, 2009) investigated the effects of Land reclamation activities on the Northern coast of Bantam. He observed that Land reclamation causes floods and erosion, reduced quality of sea water and loss of fish species and sea biota. Usually, both the reclamation site and dredging site undergo biological, physical and chemical impacts (Y, 2012). (Idowu \& Home, 2017) backs up the idea that land reclamation may impact ground water regime near coast areas as well as the coast areas opposite the reclamation area. They reported that size of reclaimed areas is one of the causes changes in groundwater dynamics. In principle, a positive consequence of Land Reclamation is that it raises the water table, and shifts 
salt water- fresh water interface seaward. That is because the reclaimed land can be an additional aquifer and rain recharge takes place over a larger area (Idowu \& Home, 2017). However, from the environmental perspective, the adverse impacts of widespread land reclamation outweigh the positive effects.

For instance, (Smolders, Plancke, Ides, Meire, \& Temmerman, 2015) noted that reclamation of wetlands leads to reduced flood storage area, leading to faster and higher storm surges being propagated inland. Extensive wetland reclamation raises water levels and reduces the resistance of the wetlands to landward flood propagation.

\section{Methodology}

Post-reclamation management are physically measurable variables, observation schedule was employed to help in taking cognizance of the physical features of residential buildings in the study zone, while descriptive survey method was used in selecting the study sites. Purposeful sampling method which according to (Ikibe \& Akande, 2018) will provide variation in the sample selected bringing to bear some specific features the researcher wishes to observe in the selected population sample. It is also noteworthy that 3-sites which are reclaimed for residential purposes was considered for the study. This was done on the basis that they share similar but yet distinct properties.

\subsection{Data Collection}

Primary data was collected using survey questionnaires, although interview and observations was also employed where necessary. This exercise was structured to extract information surrounding issues like general wetness of top surrounding soil, flooding of surrounding land and building, rising damp on floors and walls, drainage problem, depression of the ground floor, cracking of the ground floor, flooding of soak away pit and septic tank, among others.

Secondary data sources are majorly work of literature addressing the objectives of this study. Also, a survey research component was incorporated to provide the data on the research variables that could not be obtained through observation. (Himeur, et al., 2021) justified the use of case study approach in this type of research on the grounds that the study focuses on information specific to a particular context. Furthermore, it permits the researcher to concentrate on an in-depth investigation of a specific issue as it related to the subject matter.

The case studies will be Victoria Garden City (VGC) on the basis that it is fully occupied and partially reclaimed from swamp; Banana Island on the basis that it is a residential development fully reclamation from lagoon; and a glimpse into the development of Eko-Atlantic city on the basis that it's still an ongoing project, fully reclaimed from the sea, and will assist in establishing a contrast between the study sites earlier mentioned.

\subsection{Method of Data Interpretation and Analysis}

By design, this research is exploratory in nature; hence descriptive approach will be used as the method of data analysis to be employed. This will ease the interpretation of the comprehensive and qualitative data obtained for this study. In order to answer the research questions holistically, information induced from data gathering will further be subjected to inductive comparism to bridge knowledge gap (for better understanding) while results of the data analysis will be presented with reference to relatable literatures.

\section{Data Analysis and Interpretation}

In analyzing the data for this study, a comparative approach was considered on the basis of the research approach adopted. Hence, data was analysed comparing distinct features of the impact on land reclamation in the case studies. However, only VGC and Banana Island were considered for the study while Eko Atlantic was just used as guide base on the fore knowledge that land the location is still work in progress. That being said, its policy guideline is being followed to achieve the best result for this study.

For the purpose of sampling, structured questionnaires were administered on the respondents, to elicit information on the existing land management policies and the performance of the reclaimed land. Observation case scenario coupled with interview session with the estate facility management were required to get detailed information as it regards the maintenance practices within the estate. Relative importance indices were used to rank the variables with simple charts to present the results.

Efforts were made to solicit user's information that center on such theme of discussion including; occupancy, type of dwelling, and length of stay. All these put together enables an easy extraction of the views expressed in the questionnaire survey. Responses were analyzed to generate simple frequencies tables and charts.

The information contained in Table 1 below is to elicit information regarding respondents' background information. This is necessary because, it will greatly contribute to the outcome of the data gathered. However, $74 \%$ of the respondents in VGC the rightful house owner while 50.6\% of respondents in Banana Island are tenants. Also, the response shows that majority of them are married, while bulk of the houses in VGC are duplex and semi-detached. For Banana Island however, all kinds of building type were assessed with $43.5 \%, 32.9 \%$ and $23.5 \%$ for duplex, semi-detached and terrace building respectively. 


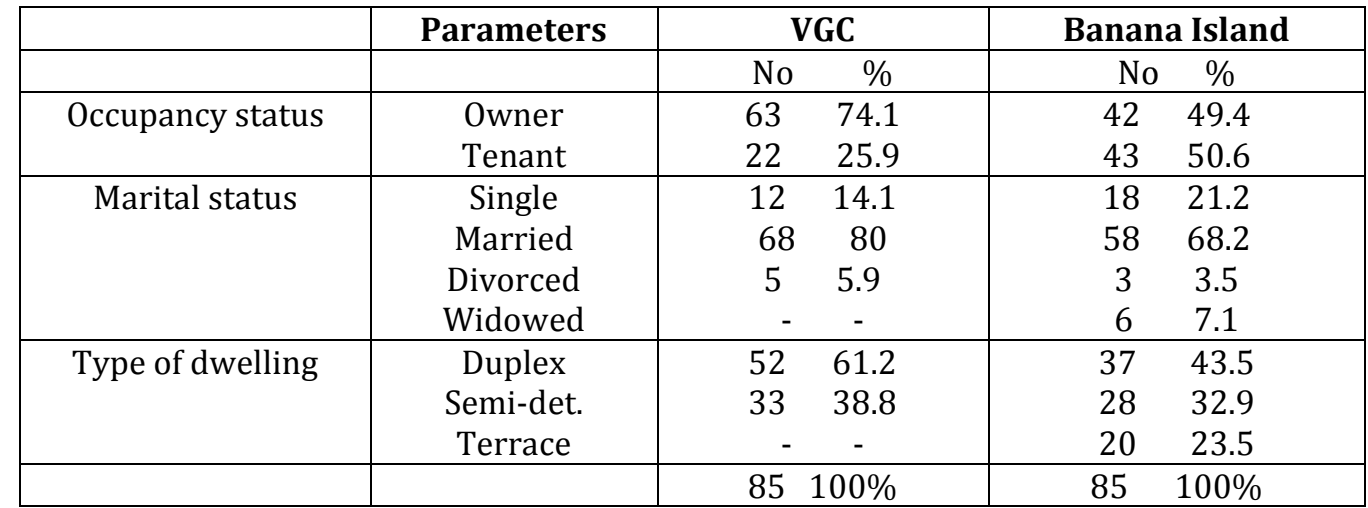

Table 1: Respondents' Information

Source:Researchers' Survey, 2020

\begin{tabular}{|c|c|c|c|c|}
\hline & Parameters & VGC & \multicolumn{2}{|c|}{ Banana Island } \\
\hline & & No $\%$ & No & $\%$ \\
\hline \multirow[t]{4}{*}{ Interior floor } & Concrete & $\begin{array}{ll}8 & 9.4\end{array}$ & 10 & 11.8 \\
\hline & Tiled & $37 \quad 43.5$ & 43 & 50.6 \\
\hline & Wooden floor & $23 \quad 27.1$ & 12 & 14.1 \\
\hline & Others & 1517.6 & 20 & 23.5 \\
\hline \multirow[t]{3}{*}{ Exterior floor } & Concrete & $5 \quad 5.9$ & 2 & 2.4 \\
\hline & Stamped & $48 \quad 56.5$ & 51 & 60 \\
\hline & Interlock & $32 \quad 37.6$ & 32 & 37.6 \\
\hline \multirow{3}{*}{$\begin{array}{c}\text { Other landscape } \\
\text { elements }\end{array}$} & Natural Green & 5261.2 & 45 & 52.9 \\
\hline & Artificial grass & $33 \quad 38.8$ & 40 & 47.1 \\
\hline & & $85100 \%$ & 85 & $00 \%$ \\
\hline
\end{tabular}

Table 2: Choice of Building Finishes

Source: Researchers' Survey, 2020

\subsection{Conditions of Building Elements}

Result of the analysis of data reflects the estates under study are high class private development. Findings however show that individual buildings are giving the will to exercise their liberty in the choice of material used as floor and wall finish. It was however observed that most houses either prefer tiled floor to wooden floor for internal floor, and combination of hard and soft landscape for exterior beauty. Further analysis reflects that there are number of problems encounter due to the nature top soil and the location of the estate. The description of these defects highlights the conditions of the part that form the building element and indicates the physical and structural soundness of the entire facility under study.

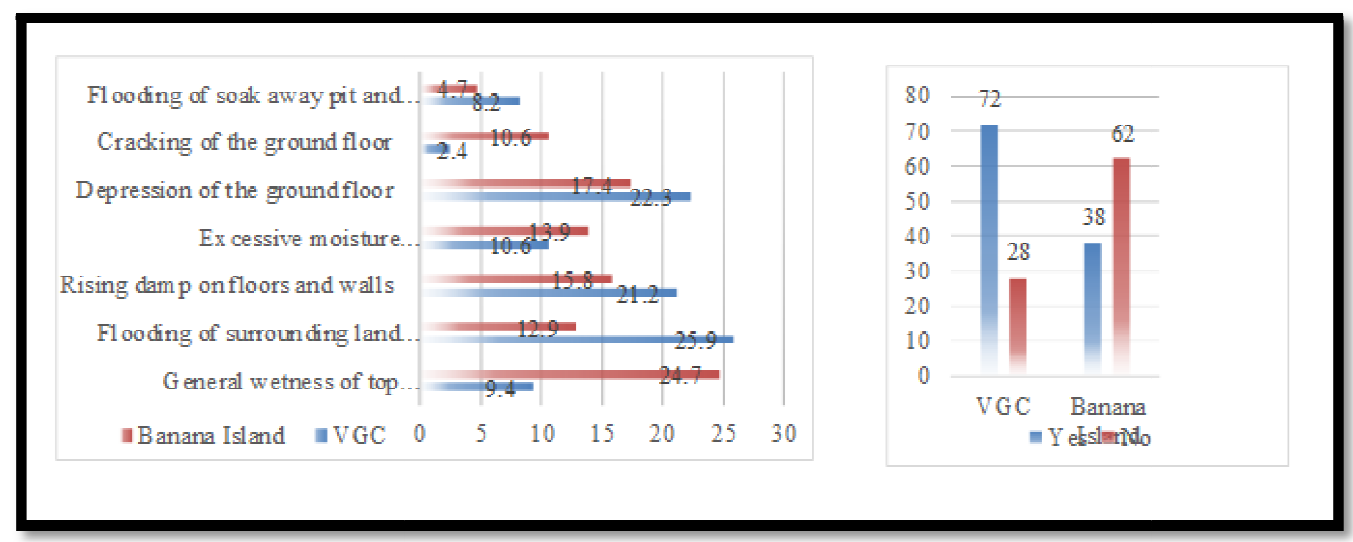

Figure 1: Observable Building Defects on Floors, Walls and External Environment

The information displayed by the charts above shows that there are environmental problems relating to the study discussion but with different gravity. The defects are more pronounced in VGC with $72 \%$ of the respondents agreeing to that, while Banana Island has just 38\%. The variables identified are such issues that affect the state of the lands, including flooding and depression of the floor which is high in VGC (25.9\% and 22.3\%), general wetness of top surrounding soil which quite high in Banana Island (24.7\%); all ranked as the most pertinent problems associated with the lands. Other important defects are rising damp in the floors and excessive moisture (21.2\% and $17.9 \%$ respectively). All these could be associated to the effect emanating from soil consolidation, excessive moisture content of the soil and/or even drainage problems. Other identified environmental issue includes flooding, general wetness of top soil, and erosion gully, in no 
particular order. The difference in the views of the experts and the dwellers draws from the emphasis of the experts on the structural stability of the soil above its service functions.

\subsection{Present State of Facilities and Their Maintenance Level}

The result of findings as displayed in figures 3.2 seek to find out whether they carry out any form of maintenance activities and know if there is any plan that guides maintenance practices. It was however gathered that the estate management is responsible for some facilities like good road, drainage, and flood control; while individual residential units are responsible for their units. The estate management makes it a point of call to prepare for problems that could come with raining season, especially flooding, hence performs routine check and advises inhabitant bout the imminent danger if there is any.

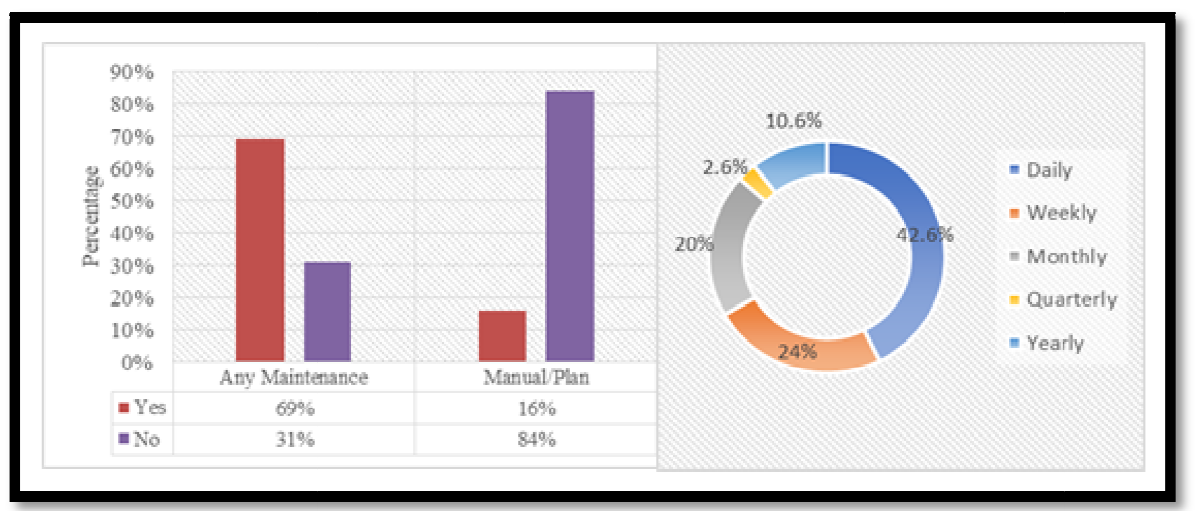

Figure 2: Maintenance Policy and Frequency of Maintenance Work Note: Daily and Weekly Indicates "Often", Monthly - "Rarely" While Quarterly \&Yearly - "Never"

Figure 2 summarizes the frequency of maintenance work carried out by users/occupants and the maintenance team. Simple majority (42.6\% and $24 \%$ ) indicated that maintenance was done on daily and weekly basis respectively, while others indicated monthly, quarterly and yearly maintenance. This result only confirms that respondents consider routine maintenance as a means of keeping the facility okay for use but not in its best shape. Study shows that this has resulted in deterioration of surrounding buildings and services due to lack of maintenance and unattended wear and tear caused by negligence, but with adequate planning and funding, a lot could still be achieved considering how importance it is not to ignore reclaimed land after development has been completed.

\section{Conclusion}

Land reclamation is not a new technology considering the level at which its being practiced to develop coastline and also turn inhabitable marshy and wetlands to usable land for building purposes. However, this study reflects how important land management is, and the magnitude of maintenance attention required to avoid degradation or other forms of environmental challenges that could threaten housing development on reclaimed parcel. Consequently, it is suggested that more attention should be drawn to post-construction maintenance even post-reclamation. Also, policy paper should be drafted, advocated and adopted to improve situations emanating from the probable effect of dampness of building, wetness of top soil and surrounding environment, and also flooding which are more or less issues identified with land reclamation. Aesthetics being a critical attribute of buildings in most low-density neighborhood as it is the case in this study should not be neglected. Hence, special attention should be given to building standards by specifying foundation types, height of foundation footing to corresponding floor level and quality of building materials. This will help to reduce the overall effect of degradation and limit maintenance cost.

\section{Acknowledgements}

We appreciate our senior colleagues for their appropriate and constructive suggestions towards the accomplishment of this great research work.

\section{References}

i. Aina, O., Ata, O., \& K.O, O. (2002). Land reclamation practices in Lagos . Conference on the City in Nigeria (pp. 282-287). Lagos : Obafemi Awolowo Univerity, Ile Ife.

ii. Himeur, Y., Alsalemi, A., Al-Kababji, A., Bensaali, F., Amira, A., Sardianos, C., \& Varlamis. (2021). Himeur, Y., Alsalemi, A., Al-Kababji, A., BenA survey of recommender systems for energy efficiency in buildings: Principles, challenges and prospects. Information Fusion, 1-21.

iii. Idowu, T. E., \& Home, P. (2017). Probable effects of sea level rise and land reclamation activities on coastlines and wetlands of Lagos Nigeria. Lagos: Lagos.

iv. Ikibe, J. H., \& Akande, O. K. (2018). Crowd Control in Public Building Designs: Current Trend and Strategies for Ecclesiastical Buildings in Abuja, Nigeria. Journal of Architecture and Construction, 25-33.

v. Priyandes, A., \& Majid, M. R. (2009). Impact of reclamation activities on the environment case study: reclamation in northern coast of Batam. Journal Alam Bina, 1511-1369. 
vi. R, D. J., P, V. G., M, L., \& J, F. (2005). Dubai's extreme reclamations . The CEDA Dredging days (2005) conference (pp. 31-45). Rotterdam: CEDA.

vii. Smolders, S., Plancke, Y., Ides, S., Meire, P., \& Temmerman, S. (2015). Role of intertidal wetlands for tidal and storm tide attenuation along a confined estuary: a model study. Natural Hazards and Earth System Sciences, 1659-1675.

viii. Y, M. (2012). Environmental impacts of dredging and land reclamation at Abu Qir Bay, Egypt. Ain Shams Engineering Journal, 1-15 